\title{
EDITORIAL
}

\section{ANEMIA OF OLD AGE}

\author{
A.M. SANFORD, J.E. MORLEY

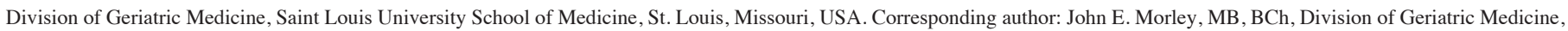 \\ Saint Louis University School of Medicine, 1402 S. Grand Blvd., M238, St. Louis, MO 63104, Email: john.morley@health.slu.edu
}

Key words: Anemia, aging, reticulocyte index.

$$
\begin{array}{r}
\text { “Anemia - a common but never normal concomitant of } \\
\text { aging” } \\
\sim \mathrm{R} \text {. Lewis } 1976(1)
\end{array}
$$

The word anemia was originally derived from the ancient Greek $(\mathrm{An}=$ not; haema $=$ blood $)$. In 1958, the World Health Organization (WHO) defined anemia as a hemoglobin concentration less than $13 \mathrm{~g} / \mathrm{dl}$ in men and less than $12 \mathrm{~g} / \mathrm{dl}$ in women. These values have been utilized for the last 50 years despite the fact that these values were not necessarily evidence-based and that numerous studies, especially in males, have suggested that the values should be higher. In 2006 Beutler and Waalen (2) utilized a large number of subjects in the WHANES-III and the Scripps-Kaiser database to more accurately determine normal values. They excluded subjects with diabetes mellitus, renal failure, elevated inflammatory markers, and those with low serum ferritin and transferrin because these frequently impact the hemoglobin level. They concluded that $13.7 \mathrm{~g} / \mathrm{dl}$ in white males and $12.9 \mathrm{~g} / \mathrm{dl}$ in black males were the appropriate normal hemoglobin levels for those under 60 years of age and $13.2 \mathrm{~g} / \mathrm{dl}$ (white), and $12.7 \mathrm{~g} /$ dl (blacks) were normal for those greater than 60 years of age. In females, hemoglobin levels of $12.2 \mathrm{~g} / \mathrm{dl}$ in whites and $11.5 \mathrm{~g} /$ $\mathrm{dl}$ in blacks were found to be normal levels for women of all ages. Race impacts hemoglobin levels, with black people having lower levels, likely due to the high frequency of alphathalassemia genes (and potentially yet un-discovered genes) in this population.

A large meta-analysis found that using the original WHO criteria, $17 \%$ of older persons were anemic (3). However, when a hemoglobin level of $<11 \mathrm{~g} / \mathrm{dl}$ was used, that percentage increased to $76 \%$. In this study, anemia was found to be more common in males than in females and more common in black people than in white people. Anemia increases with age with prevalence being as high as $2.3 \%$ to $31 \%$ in the oldest of old. There is also a large geographical variation. In one study, the prevalence of anemia in Minnesota was found to be $7 \%$ in older women and $9 \%$ in older men (4), whereas, in the English Longitudinal Study of Aging, which included study participants living in England, only 5.2\% were found to be anemic (5). In nursing homes, anemia is quite common; the prevalence ranging from $47 \%$ to $60 \%$ (6). Furthermore, studies have demonstrated that persons with anemia are more likely to be frail (7-9), fatigued (10), have impaired grip strength (11), have decreased functional status (12), more likely to fall (13), have fractures (14), be cognitively impaired (15) and have overall increased mortality (16) than their non-anemic counterparts.

The causes of anemia can be classified as those with an elevated reticulocyte index (which is the reticulocyte count corrected for hemoglobin) and those with a low reticulocyte index (Table 1). Those with an elevated reticulocyte count are either due to blood loss or hemolysis. Nutrient deficiency-i.e., vitamin B12, folate, riboflavin, and copper deficiency or protein energy malnutrition, or decreased production of red blood cells (seen in anemia of chronic disease/inflammation, anemia of chronic kidney disease-defined by the lack of erythropoetin plus inflammation, and myelodysplastic disorders) are the common causes of anemia with a low reticulocyte index. In older persons about $20 \%$ of anemia has no clear explanation and has been termed the anemia of old age (17).

Table 1

Causes of Anemia in Old Age

\begin{tabular}{ll}
\hline$\downarrow$ Reticulocyte Index & $\uparrow$ Reticulocyte Index \\
\hline Bone Marrow Failure & Hemorrhage \\
- Myelodysplasia & \\
- Anemia of Chronic Kidney Disease & Hemolysis \\
& \\
Nutritional & \\
- Iron deficiency & \\
- Vitamin B12 deficiency & \\
- Folate deficiency & \\
- Copper deficiency & \\
- Pyridoxine deficiency & \\
- Protein energy malnutrition & \\
Inflammatory & \\
- Anemia of chronic disease & \\
Idiopathic & \\
\hline
\end{tabular}




\section{THE JOURNAL OF NUTRITION, HEALTH \& AGING@}

\section{Aging and Iron Status}

Serum levels of iron and transferrin typically decline with aging (18). Conversely, serum ferritin levels increase until around 60 years of age after which they plateau (19). Additionally, serum ferritin levels are increased with inflammation, which requires a compensatory increase in serum ferritin "normal" levels from $20 \mu \mathrm{g} / \mathrm{L}$ to $40 \mu \mathrm{g} / \mathrm{L}$ to improve the sensitivity in diagnosing iron deficiency anemia. For this reason, a C-reactive protein (CRP) should be measured in conjunction with ferritin levels and helps one distinguish between iron deficiency anemia and anemia of chronic disease/ inflammation.

The soluble transferrin receptor (STfR) plays an important role in delivering iron to erythroid precursors. Because its levels rise when there is a shortage of intracellular iron, it is less sensitive to the effects of chronic inflammation. The $\mathrm{STfR} / \log$ ferritin index is considered a good measure of iron deficiency because it represents a true estimate of total body iron stores $(20,21)$. Fibroblast Growth Factor, which increases with low iron measures, has been suggested as an alternative measurement (22).

Hepcidin, which is released from the liver in response to the inflammatory cytokine, interleukin-6, inhibits the function of the iron transporter, ferroportin (Figure 1). This decreases iron absorption from the gut and prevents release of iron from macrophages into the bloodstream (23). The measurement of SSTfR/Hepcidin index may be a useful measure to predict iron deficiency (24). The role of hepcidin in the pathogenesis of the anemia of chronic disease has led to the development of a number of hepcidin antagonists (antibodies, antisense oligonucleotides and RNA interference) as potential therapeutic agents (25) in anemia of chronic disease/inflammation.

\section{Figure 1}

The role of hepcidin in the anemia of chronic disease

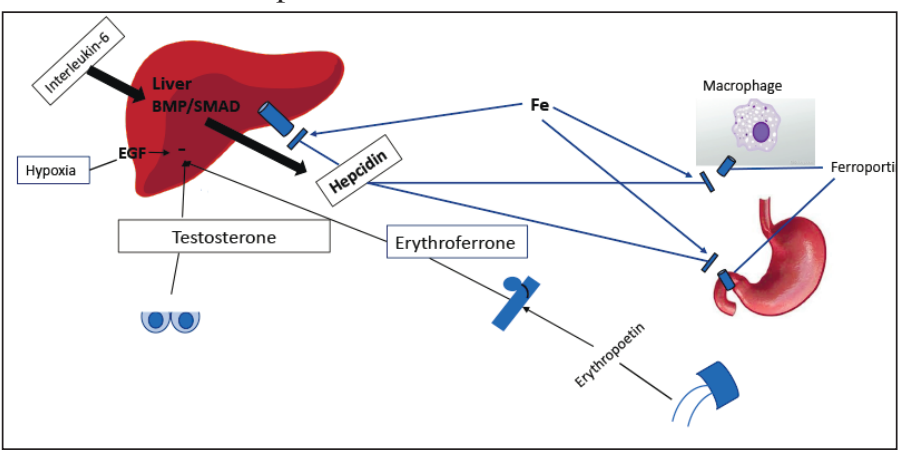

\section{Anemia of Old Age}

One possible etiologic factor for the anemia of old age is the reduction in bone marrow erythroid progenitors (26), which downstream, decreases the amount of red blood cells released into the circulation. The reduction in bone marrow cellularity begins at 30 years of age and is of the order of $30 \%$ to $50 \%$ in persons over 60 years of age. These reductions in red cell progenitors are due to epigenetic changes, oxidative damage, or reduction in telomere length. Clonal hematopoieses of indeterminate potential are relatively common in older persons, frequently presenting with mild leukopenia and anemia and may be an unrecognized cause of anemia of old age.

The cytokine-related aging process or "inflamm-aging" also contribute to the anemia of old age (27). Older persons have an increase in adiposity which increases chronic inflammation and leads to increased hepcidin production (28) In addition, in older persons there is often a decrease in erythropoietin production and also a decline in receptor sensitivity to erythropoietin (29). Eryptosis (apoptosis of red blood cells) can be stimulated by inflammation (30). With aging, phosphatidylserine moves to the red cell surface, making the red cells more susceptible to being ingested by macrophages. Protein energy malnutrition, which is common in older persons, also leads to anemia $(31,32)$.

Testosterone levels decline in males with aging, resulting in a lowering of the hemoglobin and hematocrit (33). Testosterone administration in hypogonadal males reverses this process and leads to an increase in erythropoietin levels and a decrease in hepcidin. This decrease in hepcidin results in an increase in ferroportin expression, leading to increased iron absorption and release into the circulation $(34,35)$.

The causes of anemia of old age are summarized in Figure 2 and the diagnostic characteristics in Table 2 .

Figure 2

Etiology of the Anemia of Old Age

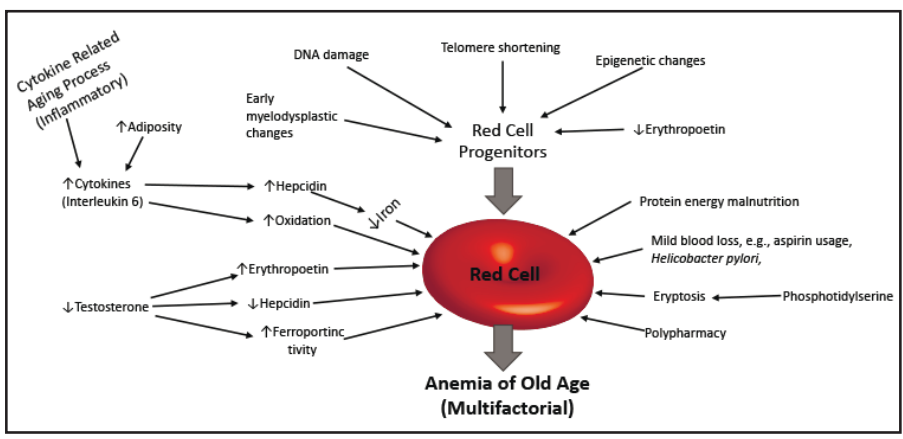

Conclusion

Anemia is a common condition in older persons. There are a variety of treatable causes and when anemia is identified physicians should follow a simple diagnostic algorithm to make the appropriate diagnosis (Figure 3 ). 
ANEMIA OF OLD AGE

Table 2

Comparison of Anemia of Old Age with Iron Deficiency Anemia and Anemia of Chronic Disease

\begin{tabular}{llll}
\hline & Anemia of Old Age & Iron Deficiency Anemia & Anemia of Chronic Disease \\
\hline Leukocytes & Normal or slightly low & Normal & Normal \\
Iron & Normal & Decreased & Normal \\
Transferrin & Normal & Decreased & Normal \\
Ferritin & Normal & Decreased & Increased \\
Soluble Transferrin Receptors (sTFR) & Normal & Increased & Normal \\
sTFR/log Ferritin & Normal & Increased & Normal \\
Fibroblast Growth Factor & Normal & Increased & Normal \\
Hepcidin & Normal or mildly increased & Normal & Increased \\
Neopterin & Increased slightly & Normal & Increased \\
Interleukin-6 & Mild increase & Normal & Increased \\
CRP & Normal or increased & Normal & Increased \\
Erythropoetin & Decreased & Increased & Normal \\
Albumin & Mild decrease & Normal & Decreased \\
\hline
\end{tabular}

\section{Figure 3}

Algorithm for Diagnosis of Anemia in Older Persons

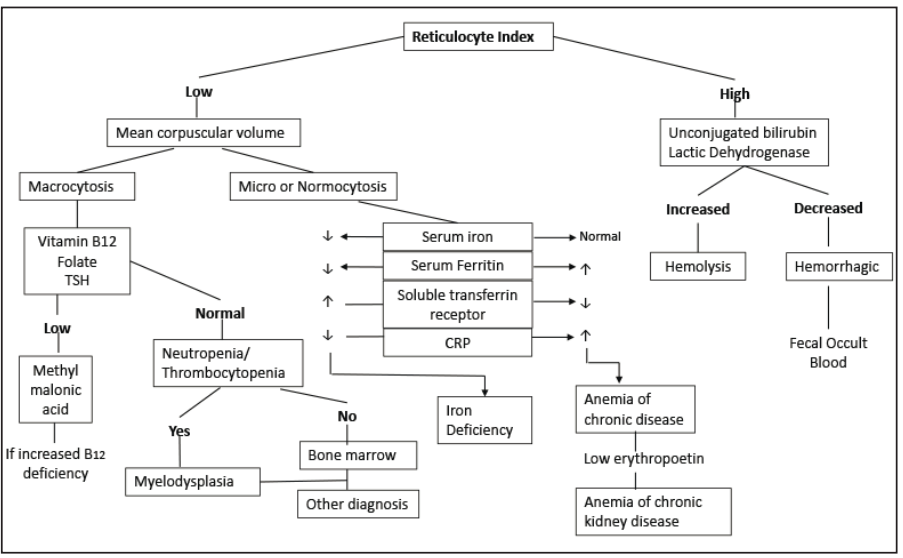

Disclosures: The authors declare there are no conflicts.

\section{References}

1. Lewis R. Anemia a common but never normal concomitant of aging. Geriatrics 1976;31:53-60

2. Beutlere E, Waalen J. The definition of anemia: What is the lower limit of normal of blood hemoglobin concentration? Blood 2006;107:1747-1750.

3. Gaskell H, Derery S, Andrew Moore R, McQuay HJ. Prevalence of anaemia in older persons: Systematic review. BMC Geriatr 2008;8:1.

4. Halawi R, Moukhadder H, Taher A. Anemia in the elderly: A consequence of aging? Expert Rev Hematol 2017;10:327-335.

5. Hamer M, Molloy GJ. Cross-sectional and longitudinal associations between anemia and depressive symptoms in the English longitudinal study of ageing. J Am Geriat Soc April 28 2009;57(5). https://doi.org/10.1111/j.1532-5415.2009.02250.x (Free access)

6. Morley JE. Anemia in the nursing homes: A complex issue. J Am Med Dir Assoc 2012;13:191-194

7. Palmer K, Vetrano DL, Marengoni A, et al. The relationship between anaemia and frailty: A systematic review and meta-analysis of observational studies. J Nutr Health aging 2018;22:965-974

8. Palmer K, Vetrano DL, Marengoni A, et al. The relationship between anaemia and frailty: A systematic review and meta-analysis of observational studies. J Nutr Health Aging 2018;22:965-974.

9. Pires Corona L, Drumond Andrade FC, de Oliveira Duarte YA, Lebrao ML. The relationship between anemia, hemoglobin concentration and frailty in Brazilian older adults. J Nutr Health Aging 2015;19:935-940

10. Morley JE. Rapid geriatric assessment: Secondary prevention to stop age-associated disability. Clin Geriatr Med 2017;33:431-440.

11. Joosten E, Detroyer E, Milisen K. Effect of anaemia on hand grip strength, walking speed, functionality and 1 year mortality in older hospitalized patients. BMC Geriat 2016;16:153. Doi: 10.1186/s12877-016-0326-y.

12. Bosco Rde M, Assis EP, Pinheiro RR, et al. Anemia and functional capacity in elderly Brazilian hospitalized patients. Cad Saude Publica 2013;29:1322-1332.

13. Hopstock LA, Utne EB, Horsch A, Skjelbakken T. The association between anemia and falls in community-living women and men aged 65 years and older from the fifth Tromso Study 2001-02: A replication study. BMC Geriatr 2017;17:292.d doi: 10.1186/s12877-017-0689-8.

14. Morley JE. Frailty, falls, and fractures. J Am Med Dir Assoc 2013;14:149-151.

15. Yavuz BB, Cankurtaran M, Haznedaroglu IC, et al. Iron deficiency can cause cognitive impairment in geriatric patients. J Nutr Health Aging 2012;16:220-224.

16. Fowler AJ, Ahmad T, Phull MK, et al. Meta-analysis of the association between preoperative anaemia and mortality after surgery. Br J Surg 2015;102:1314-1324.

17. Malaguarnera M1, Di Fazio I, Vinci E, Bentivegna P, Mangione G, Romano M.Haematologic pattern in healthy elderly subjects. Panminerva Med. 1999 Sep;41(3):227-31.

18. Fairweather-Tait SJ, Wawer AA, Gillings R, Jennings A, Myint PK. Iron status in the elderly. Mech Ageing Dev 2014;171:136-137.

19. Wawer AA, Jennings A, Fairweather-Tait SJ. Iron status in the elderly: A review of recent evidence. Mech Ageing Dev 2018;175:55-73.

20. Shin DH, Kim HS, Park MJ, et al. Utility of access soluble transferrin receptor (sTfR) and sTfR/log Ferritin Index in diagnosing iron deficiency anemia. Ann Clin Lab Sci 2015;45(4):396-402.

21. Harms K, Kaiser T. Beyond soluble transferrin receptor: Old challenges and new horizons. Best Pract Res Clin Endocrinol Metab 2015;29:799-810.

22. Bozentowicz-Wikarek M, Kocelak P, Owczarek A, et al. Plasma fibroblast growth factor 23 concentration and iron status. Does the relationship exist in the elderly population? Clin Biochem 2015;48:431-436.

23. Roth MP, Meynard D, Coppin H. Regulators of hepcidin expression. Vitamins and Hormones 2019;110:101-111.

24. Karlsson T. Evaluation of a competitive hepcidin ALISA assay in the differential diagnosis of iron deficiency anaemia with concurrent inflammation and anaemia of inflammation in elderly patients. Karlsson J Inflammation 2017;14:21. Doi:10.1187/ s12950-017-0166-3.

25. Sun CC, Vaja V, Babitt JL, Lin HY. Targeting the hepcidin-ferroportin axis to develop new treatment strategies for anemia of chronic disease and anemia of inflammation. Am J Hematol 2012;87:392-400.

26. Mahlknecht U, Kaiser S. Exp Ther Med. Age-related changes in peripheral blood counts in humans. $2010 \mathrm{Nov}$;1(6):1019-1025 


\section{THE JOURNAL OF NUTRITION, HEALTH \& AGING@}

27. Morley JE, Baumgartner RN. Cytokine-related aging process. J Gerontol A Biol Sci Med Sci 2004;59:M924-M929.

28. Przybyszewska J, Zekanowska E, Kedziora-Kornatowska K, et al. Prohepcidin and iron metabolism parameters in the obese elderly patients with anemia. J Nutr Health Aging 2011;15:259-264.

29. Stauder R, Valent P, Theurl I. Anemia at older age: Etiologies, clinical implications, and management. Blood 2018;131:505-514.

30. Lang E, Lang F. Triggers, inhibitors, mechanisms, and significance of eryptosis: The Suicidal erythrocyte death. Biomed Res Int 2015;2015:513518. Doi: 10.1155/2015/513518. Epub 2015, March 4.

31. Frangos E, Trombetti A, Graf CE, et al. Malnutrition in very old hospitalized patients:
A new etiologic factor of anemia? J Nutr Health Aging 2016;20:705-713.

32. Morley JE. Editorial: Defining undernutrition (malnutrition) in older persons. J Nutr Health Aging 2018;22:308-310.

33. Bassil N, Morley JE. Late-life onset hypogonadism: A review. Clin Geriatr Med 2010;26:197-222.

34. Dhindsa S, Ghanim H, Batra M, et al. Effect of testosterone on hepcidin, ferroportin, ferritin and iron binding capacity in patients with hypogonadotropic hypogonadism and type 2 diabetes. Clin Endocrinol (Oxf). 2016;85:772-780.

35. Guo W, Bachman E, Li M, et al. Testosterone administration inhibits hepcidin transcription and is associated with increased iron incorporation into red blood cells. Aging cell. 2013;12:280-291. 